\title{
PENERAPAN LINGKUNGAN KERJA DAN DISIPLIN KERJA TERHADAP KINERJA PEGAWAI DI DINAS PERHUBUNGAN KOTA SERANG
}

\author{
Dewi Asih ${ }^{1}$, Pramudi Harsono ${ }^{2}$ \\ ${ }^{1,2}$ Fakultas Ekonomi Jurusan Manajemen, Universitas Bina Bangsa \\ pramudi1909@gmail.com
}

\begin{abstract}
ABSTRAK
Kinerja adalah penampilan pekerjaan dan hasil yang dicapai oleh seseorang baik dalam barang atau produk atau dalam bentuk layanan yang biasanya digunakan sebagai dasar untuk penilaian diri karyawan atau organisasi kerja yang bersangkutan yang mencerminkan pengetahuan karyawan tentang pekerjaannya. Semakin tinggi kualitas dan kuantitas pekerjaan, semakin tinggi kinerjanya. Penelitian ini bertujuan untuk mengetahui dampak lingkungan kerja dan disiplin kerja secara sedikit demi sedikit terhadap kinerja karyawan dan efek lingkungan kerja serta disiplin kerja bersama terhadap kinerja pegawai di Dinas Perhubungan Kota Serang. Jenis penelitian yang digunakan adalah penelitian kuantitatif. Penelitian dilakukan di Dinas Perhubungan Kota Serang. Jumlah responden adalah 35 orang. Penelitian ini mendistribusikan kuesioner kepada karyawan. Teknik pemrosesan dan analisis data menggunakan SPSS versi 25. Hasil penelitian ini menunjukkan bahwa lingkungan kerja (X1) berpengaruh pada kinerja karyawan $(\mathrm{Y})$ dengan nilai tcount $>$ ttable $(1.854>1.693)$. Disiplin kerja $(\mathrm{X} 2)$ berpengaruh pada kinerja karyawan $(\mathrm{Y})$ dengan nilai tcount $>$ ttable $(3.086>1.693)$ dan secara bersamaan atau bersamaan menunjukkanbahwa Fcount $>$ Ftable, yaitu $=28.400>3,29$. Artinya ada pengaruh antara Lingkungan Kerja dan Disiplin Kerja bersama terhadap Kinerja Pegawai di Dinas Perhubungan Kota Serang. Kesimpulan yang diperoleh menunjukkan bahwa lingkungan kerja sebagian mempengaruhi kinerja karyawan, sebagian disiplin kerja mempengaruhi kinerja karyawan dan secara bersamaan atau bersamaan lingkungan kerja dan disiplin kerja mempengaruhi kinerja karyawan.
\end{abstract}

Kata kunci : Lingkungan Work, Disiplin Kerja, Kinerja Karyawan

\begin{abstract}
Performance is the appearance of work and the results achieved by a person either in goods or products or in the form of services which are usually used as a basis for self-assessment of the employee or the work organization concerned which reflects the employee's knowledge about his work. The higher the quality and quantity of the work, the higher the performance. This study aims to determine the effect of work environment and work discipline on a piecemeal basis on employee performance and the effect of work environment and work discipline together on employee performance at the Department of Transportation of Serang City. The type of research used is quantitative research. The research was conducted at the Department of Transportation of Serang City. The number of respondents is 35 people. This study distributed questionnaires to employees. The data processing and analysis technique used SPSS version 25. The results of this study indicate that the work environment (X1) has an effect on employee performance $(Y)$ with a value of tcount $>$ ttable $(1,854>1,693)$. Work discipline $(X 2)$ has an effect on employee performance $(Y)$ with a value of tcount $>$ ttable $(3,086>1,693)$ and simultaneously or simultaneously shows that Fcount $>$ Ftable, namely $=28,400>3,29$. This means that there is an influence between the Work Environment and Work Discipline together on the Performance of Employees at the Serang City Transportation Service. The conclusion obtained shows that the work environment partially affects employee performance, partially work discipline affects employee performance and simultaneously or simultaneously the work environment and work discipline affects employee performance.
\end{abstract}

Keywords : Work Environment, Work Discipline, Employee Performance 
Keberhasilan suatu organisasi atau instansi tidak terlepas kaitannya dari sumber daya manusia yang dimiliki, karena sumber daya manusia yang akan mengatur dan mengelola sumber daya lain yang dimiliki organisasi untuk membantu mewujudkan tujuan organisasi itu sendiri dan sumber daya manusia juga merupakan asset yang perlu dikembangkan secara efektif dan efesin.

Selain itu seorang pegawai dituntut untuk bisa bekerja sesuai dengan standar yang telah ditetapkan oleh instansi, sebab kinerja yang baik adalah kinerja yang optimal yang membantu mencapai tujuan ataupun target dari sebuah organisasi atau instansi. Agar kinerja pegawai selalu konsisten maka setidak-tidaknya organisasi atau instansi harus memperhatikan lingkungan kerja disekitar pegawai yang dapat mempengaruhi kemampuan pegawai dalam menjalankan tugasnya serta disiplin kerja yang tinggi dari pegawai.

Kinerja adalah penampilan kerja maupun hasil yang dicapai oleh seseorang baik barang atau produk maupun berupa jasa yang biasanya digunakan sebagai dasar penilaian atas diri karyawan atau organisasi kerja yang bersangkutan yang mencerminkan pengetahuan karyawan tentang pekerjaannya itu. Semakin tinggi kualiltas dan kuantitas hasil kerjanya maka semakin tinggi pula kinerjanya.

Sementara menurut Irham Fahmi, Kinerja adalah hasil yang didapat oleh suatu oranisasi baik bersifat profit oriented ataupun non profit oriented, yang dihasilkan selama satu periode tertentu. Untuk meningkatkan kinerja yang baik dapat dilakukan dengan mengkondisikan lingkungan kerja dan meningkatkan disiplin kerja sehingga pegawai menjadi lebih bersemangat untuk menjalankan tugas-tugasnya.

Lingkungan kerja adalah segala sesuatu yang ada disekitar para pekerja/karyawan yang dapat mempengaruhi kepuasan kerja karyawan dalam melaksanakan pekerjaannya sehingga akan diperoleh hasil kerja yang maksimal, dimana dalam lingkungan kerja tersebut terdapat fasilitas kerja yang mendukung karyawan dalam penyelesaian tugas yang bebankan kepada karyawan guna meningkatkan kerja karyawan dalam suatu perusahaan.

Selain faktor lingkungan kerja, yang mempengaruhi kinerja pegawai adalah faktor disiplin kerja. Menurut Handoko (2011) Disiplin adalah kegiatan manajemen untuk menjalankan standar-standar organisasional.

\section{Tujuan Penelitian}


Prosiding The 1st National Conference on Applied Business, Education, \& Technology (NCABET)"

Unversitas Bina Bangsa 2021

DOI Article : 10.46306/ncabet.v1i1.55

Berdasarkan latar belakang dan rumusan masalah yang ada, maka penelitian ini

dilakukan dengan tujuan :

1. Untuk mengetahui Pengaruh Langsung lingkungan kerja (X1) terhadap Kinerja Pegawai (Y) Di Dinas Perhubungan Kota Serang

2. Untuk mengetahui pengaruh langsung disiplin kerja (X2) terhadap Kinerja Pegawai (Y) Di Dinas Perhubungan Kota Serang

3. Untuk menganalisis dan mengetahui pengaruh langsung lingkungan kerja (X1) dan disiplin kerja (X2) secara bersama-sama terhadap Kinerja Pegawai (Y) Di Dinas Perhubungan Kota Serang

\section{Kinerja Pegawai}

Kinerja dalam bahasa inggris disebut dengan job performance atau actual performance atau level of performance, yang merupakan tingkat keberhasilan pegawai dalam menyelesaikan pekerjaanya. Kinerja bukan merupakan karakteristik individu, seperti bakat, tau kemampuan, namun merupakan perwujudan dari bakat atau kemampuan itu sendiri. Kineja, performance, atau prestasi kerja adalah penampilan kerja maupun hasil yang dicapai oleh seseorang baik barang/produk maupun berupa jasa yang biasanya digunakan sebagai dasar penilaian atas diri karyawan atau organisasi kerja yang bersangkutan yang mencerminkan pengetahuan karyawan tentang pekerjaannya itu. Semakin tinggi kualiltas dan kuantitas hasil kerjanya maka semakin tinggi pula kinerjanya.

Kinerja pegawai pada dasarnya diukur sesuai dengan kepentingan organisasi, sehingga indikator dalam pengukurannya disesuaikan dengan kepentingan organisasi itu sendiri. Mondy, Noe, Premeaux dalam Donni Juni Priansa menyatakan bahwa pengukuran kinerja dapat dilakukan dengan menggunakan dimensi :

a. Kuantitas pekerjaan (Quality Of Work)

Kuantitas pekerjaan berhubungan dengan volume pekerjaan dari produktivitas Kerja yang dihasilkan oleh pegawai dalam kurun waktu tertentu

b. Kualitas pekerjaan (Quality Of Work)

Kualitas pekerjaan berhubungan dengan pertimbangan ketelitian revisi kerapian dan kelengkapan di dalam mengenai tugas-tugas yang ada dalam organisasi

c. Kemandirian (Dependability) 
Prosiding The 1st National Conference on Applied Business, Education, \& Technology (NCABET)"

Unversitas Bina Bangsa 2021

DOI Article : $10.46306 /$ ncabet.v1i1.55

Ketepatan waktu maksudnya merupakan di mana kegiatan tersebut dapat diselesaikan atau suatu hasil omset dapat dicapai dengan batas waktu yang telah ditetapkan sebelumnya

d. Inisiatif (Initiative)

Insentif berkenan dengan pertimbangan kemandirian, fleksibilitas berpikir dan kesediaan untuk menerima tanggung jawab

e. Adaptabilitas (Adaptability)

Adaptabilitas berkenaan dengan kemampuan untuk beradaptasi, mempertimbangkan kemampuanuntuk bereaksi terhadap mengubah kebutuhan dan kondisi-kondisi.

\section{f. Kerjasama (cooperation)}

Kerjasama berkaitan dengan pertimbangan kemampuan untuk bekerja sama dengan orang lain. Apakah assignements mencangkup lembut dengan sepenuh hati.

\section{Lingkungan Kerja}

Lingkungan kerja adalah segala sesuatu yang ada disekitar para pekerja/karyawan yang dapat mempengaruhi kepuasan kerja karyawan dalam melaksanakan pekerjaannya sehingga akan diperoleh hasil kerja yang maksimal, dimana dalam lingkungan kerja tersebut terdapat fasilitas kerja yang mendukung karyawan dalam penyelesaian tugas yang bebankan kepada karyawan guna meningkatkan kerja karyawan dalam suatu perusahaan. Sutrisno menyatakan bahwa lingkungan kerja adalah keseluruhan sarana dan prasarana kerja yang ada di sekitar karyawan yang sedang melakukan pekerjaan yang dapat mempengaruhi pelaksanaan pekerjaan, lingkungan kerja ini meliputi tempat bekerja, fasilitas, dan alat bantu pekerjaan, kebersihan, pencayahaan, ketenangan, termasuk juga hubungan kerja antar karyawan.

Menurut Sedarmayanti secara garis besar jenis lingkungan kerja terbagi menjadi dua, yakni:

1. lingkungan kerja fisik.

2. Lingkungan kerja non fisik.

Lingkungan kerja fisik menurut Sedarmayanti adalah semua yang terdapat di sekitar tempat kerja dan yang dapat memengaruhi pegawai baik secara langsung maupun tidak langsung. Menurut Nitisemito, dalam jurnal iwan Setiawan (2018) indikator yang digunakan dalam variabel ini adalah:

1. Penerangan 
2. Suhu Udara

3. Kebersihan

4. Suara bising

5. Penggunaan warna

6. Ruang gerak

7. Keamanan

\section{Disiplin Kerja}

Pengertian disiplin kerja adalah suatu tata tertib atau peraturan yang dibuat oleh manajemen suatu organisasi, disahkan oleh dewan komisaris atau pemilik modal, disepakati oleh serikat pekerja dan diketahui oleh Dinas Tenaga Kerja seterusnya orangorang yang tergabung dalam organisasi tunduk pada tata tertib yang ada dengan rasa senang hati, sehingga tercipta dan terbentuk melalui proses dari serangkaian prilaku yang menunjukan nilai-nilai ketaatan, kepatuhan, keteraturan, dan ketertiban,

Menurut Handoko Disiplin adalah kegiatan manajemen untuk menjalankan standar-standar organisasional. Dimensi dan indikator disiplin kerja dapat dilaksanakan oleh semua anggota atau pegawai yang bekerja pada suatu organisasi, adalah:

Dimensi ketaatan waktu, dengan indikator:

1. Masuk Kerja Tepat Waktu

2. Penggunaan Waktu Secara Efektif

3. Tidak Pernah Mangkir/Tidak Kerja

Dimensi tanggung jawab kerja, dengan indikator :

1. Mematuhi Semua peraturan organisasi atau perusahaan

2. Target pekerjaan

3. Membuat laporan kerja harian

\section{METODE PENELITIAN}

Penelitian ini dilakukan dengan menggunakan pendekatan metode survey. Pada penelitian ini merupakan peneilitan kuantitatif, penelitian untuk menentukan hubungan antar variabel dalam sebuah populasi. Penelitian ini menggunakan pendekatan deskriptif analistik yaitu melihat hubungan sebab-akibat. Pernyataan tentang validitas dan pencarian hal-hal penting tentang hubungan tersebut dengan mendeskripsikan masing-masing variabel terlebih dahulu. Teknik pengumpulan data digunakan adalah wawancara dan pemberian kuesioner yang disebarkan kepada responden yang terpilih dengan menggunakan metode skala likert. 
Prosiding The 1st National Conference on Applied Business, Education, \& Technology (NCABET)"

Unversitas Bina Bangsa 2021

DOI Article : $10.46306 /$ ncabet.v1i1.55

Populasi dan Sampel

Dalam penelitian ini yang menjadi populasi adalah pegawai Dinas Perhubungan Kota Serang yang terdiri dari 35 Pegawai Negeri Sipil (PNS). Sedangkan sampel diambil berdasarkan dengan teknik sampel jenuh. Jadi jumlah sampel adalah sebanyak 35 responden

\section{Pengujian Uji validtas dan reliabilitas}

\section{a. Uji validitas}

Validitas merupakan derajat ketepatan antara data yang terjadi pada obyek penelitian dengan data yang dapat dilaporkan oleh peneliti. Dengan demikian data yang valid adalah data "yang tidak berbeda" antar data yang dilaporkan oleh peneliti dengan data yang sesungguhnya terjadi pada obyek penelitian. Dalam penelitian ini peneliti menggunakan pengujian validitas rumusan Product Moment sebagai berikut :

\begin{tabular}{l} 
Rxy $=$ \\
$\mathrm{N} \Sigma \mathrm{xy}-(\Sigma \mathrm{X})(\Sigma \mathrm{Y})$ \\
\hline
\end{tabular}

keterangan:

$$
\begin{array}{ll}
\text { rxy } & : \text { Koefisien kolerasi } \\
\sum \mathrm{X} & : \text { Jumlah seluruh skor butir total } \\
\sum \mathrm{y} & : \text { Jumlah skor total } \\
\mathrm{N} & \text { : Jumlah sampel }
\end{array}
$$

\section{b. Uji Reliabilitas}

Pengertian reliabilitas sebagai konsistensi sebuah hasil penelitian dengan menggunakan berbagai metode penelitian dalam kondisi (tempat dan waktu ) yang berbeda. Tujuan utama uji reliabilitas instrumen penelitian ialah untuk mengukur konsistensi alat ukur yang digunakan peneliti kuantitatif.

\section{HASIL DAN PEMBAHASAN}

\section{Analisis Regresi Linier Berganda}

Perhitungan regresi linier berganda antara lingkungan kerja, disiplin kerja terhadap kinerja pegawai dengan dibantu program SPSS dalam proses perhitungannya dapat diperoleh hasil sebagai berikut: 
Prosiding The 1st National Conference on Applied Business, Education, \& Technology (NCABET)"

Unversitas Bina Bangsa 2021

DOI Article : $10.46306 /$ ncabet.v1i1.55

Hasil uji koefisien Determinasi dan koefisien korelasi berganda menunjukkan nilai R sebesar 0,800. Hal ini berarti bahwa hubungan atau korelasi antara faktor-faktor yang mempengaruhi kinerja pegawai adalah kuat karena $>0,50$.

Nilai $R$ Square sebesar 0,640 atau 64\%, ini menunjukkan bahwa variabel kinerja pegawai yang dapat dijelaskan variabel lingkungan kerja dan disiplin kerja adalah sebesar 64\%, sedangkan sisanya $36 \%$ dijelaskan faktor-faktor lain yang tidak disertakan dalam model penelitian ini.

\section{Pengujian hipotesis}

a. Nilai thitung X1 diketahui sebesar 1.854 dimana selanjutnya dibandingkan dengan nilai ttabel sebesar 1,693. Dengan demikian terlihat thitung lebih besar dari ttabel (1.854 > 1,693) maka menerima H0 dan menolak H1. Jadi dapat dikatakan variabel lingkungan kerja berpengaruh signifikan terhadap kinerja pegawai di Dinas Perhubungan Kota Serang

b. Nilai thitung X2 diketahui sebesar 3.086 dimana selanjutnya dibandingkan dengan nilai ttabel sebesar 1,693. Pada tahap komparasi tersebut mengindikasikan bahwa nilai thitung > ttabel (3.086> 1,693). Jadi dapat dikatakan variabel disiplin kerja berpengaruh signifikan terhadap kinerja pegawai di Dinas Perhubungan Kota Serang

Tabel 4.

\begin{tabular}{|c|c|c|}
\hline Uji $\boldsymbol{F}$ F hitung & Signifkansi & Keterangan \\
\hline 28.400 & 0,000 & Berpengaruh \\
\hline
\end{tabular}

Dari tabel di atas dapat dilihat bahwa nilai Fhitung dengan tingkat signifikansi 0,000 (di bawah 0,05) sebesar 28.400. Berdasarkan tingkat signifikansinya, berarti variabel independen yang terdiri dari lingkungan kerja dan disiplin kerja mempunyai pengaruh signifikan terhadap variabel dependennya yaitu kinerja pegawai (Y).

\section{KESIMPULAN DAN SARAN}

\section{Kesimpulan}

Berdasarkan hasil analisis data penelitian ini peneliti dapat mengambil kesimpulkan bahwa :

1. Terdapat pengaruh antara Lingkungan Kerja terhadap Kinerja Pegawai. Hal ini dibuktikan dengan hasil perhitungan nilai $t_{\text {tabel }}$ sebesar 1,693 dan $t_{\text {hitung }}$ sebesar 
Prosiding The 1st National Conference on Applied Business, Education, \& Technology (NCABET)"

Unversitas Bina Bangsa 2021

DOI Article : 10.46306/ncabet.v1i1.55

1,854. Karena nilai $\mathrm{t}_{\text {hitung }}$ lebih besar dari $\mathrm{t}_{\text {tabel }}\left(\mathrm{t}_{\text {hitung }} 1,854>\mathrm{t}_{\text {tabel }} 1,693\right)$ maka Ha diterima Ho ditolak.

2. Terdapat pengaruh antara Disiplin Kerja terhadap Kinerja Pegawai. Hal ini dibuktikan dengan hasil perhitungan nilai nilai tabel sebesar 1,693 dan thitung sebesar 3,086. Karena nilai thitung lebih besar dari tabel ( $\mathrm{t}_{\text {hitung }} 3,086>\mathrm{t}_{\text {table }}$ 1,693), maka Ha diterima Ho ditolak.

3. Secara simultan dengan tingkat keyakinan 5\%. Diketahui nilai $\mathrm{F}_{\text {tabel }}$ sebesar 3,29. Dari hasil perhitungan didapat nilai $F_{\text {hitung }}=28.400$, untuk menentukan apakah pengaruhnya signifikan atau tidak, maka dilakukan perbandingan nilai $\mathrm{F}_{\text {hitung }}=$ 28.400> $\mathrm{F}_{\text {tabel }}$ 3,29. Berdasarkan kriteria dan hasil perhitungan, dapat disimpulkan bahwa secara bersama-sama lingkungan kerja dan disiplin kerja berpengaruh terhadap kinerja pegawai di Dinas Perhubungan Kota Serang.

\section{Saran}

Berdasarkan hasil pembahasan penelitian dan kesimpulan yang diambil dalam penelitian ini, dapat di ajukan beberapa saran sebagai berikut :

1. Bagi Dinas Perhubungan Kota Serang di harapkan agar lebih meningkatkan kinerja pegawai melalui lingkungan kerja dan disiplin kerja , karena penelitian membuktikan bahwa lingkungan kerja dan disiplin kerja dapat mempengaruhi kinerja pegawai.

2. Dari segi lingkungan kerja diharapkan Dinas Perhubungan kota serang dapat lebih memperhatikan lingkungan kerja di sekitar pegawai, sirkulasi udara dalam bekerja harus lebih baik lagi, kebersihan yang sudah ada harus di jaga oleh seluruh pegawai, penerangan dan keamanan yang sudah ada afar lebih ditingkatkan lagi agar suasana bertambah nyaman dan aman.

3. Dinas Perhubungan Kota Serang diharapkan mampu meningkatkan disiplin kerja pegawai agar lebih baik dari sebelumnya dengan tetap memperhatikan aturan yang telah ada dalam kantor mengenai kedisiplinan serta menambahkan beberapa aturan baru berupa sanksi tegas terhadap pegawai yang tidak disiplin terutama yang berkaitan dengan ketepatan waktu saat bekerja

\section{DAFTAR PUSTAKA}

Anwar Prabu Mangkunegara, 2013, Manajemen Sumber Daya Manusia. Perusahaan, Remaja Rosdakarya, Bandung.

Ariyani, Rita Ivana. 2016. Pengaruh Gaya Kepemimpinan dan Loyalitas Karyawan terhadap Kinerja Karyawan di Rumah Sakit Islam Hidayatullah Yogyakarta. Jurnal Medicoeticolegal dan Manajemen Rumah Sakit vol. 5 nomor 2: 136-142. 
Prosiding The 1st National Conference on Applied Business, Education, \& Technology (NCABET)"

Unversitas Bina Bangsa 2021

DOI Article : $10.46306 /$ ncabet.v1i1.55

Bejo Siswanto. 2011. Manajemen Tenaga Kerja Indonesia Pendekatan Administratif dan Operasional. Jakarta: Bumi Aksara

Afandi, P. (2016). Concept \& Indicator Human Resources Management For Management Researth. Yogyakarta: Deepublish.

Akhmad , F., \& Rusdi Hidayat. (2020). Manajemen Kinerja. Jawa Timur: Airlangga University Press.

Bahri, M. S. (2018). Pengaruh Kepemimpinan, Lingkungan Kerja Budaya Organisasi dan Motivasi Terhadap Kepuasan Kerja Yang Berimplikasi Terhadap Kinerja Dosen. Surabaya: CV.Jakad Publishing.

Fahmi , I. (2011). Manajemen Kinerja : Teori Dan Aplikasi. Bandung: Alfabeta.

Handoko, T. H. (2011). Manajemen Personalia \& Sumberdaya Manusia. Yogyakarta: BPFEYogyakarta.

Mangkunegara, A. A. (2017). Manajemen Sumber Daya Manusa Perusahaan. Bandung: PT. Remaja Rosdakarya.

Priansa, D. J. (2014). Perencanaan Dan Pengembangan Sumber Daya Manusia. Bandung: Alfabeta.

Rahardi, D. R. (2010). Manjemen Kinerja Sumber Daya Manusia. Malang: Tunggal Mandiri.

Suaryo, Y., \& Dkk. (2018). Manajemen Sumber Daya Manusia Kompensasi Tidak Langsung Dan Lingkungan Kerja Fisik. Yogyakarta: Andi.

Sutisno, E. (2019). Sumber Daya Manusiah. Jakarta: Prenadamedia Group.

W, M. E. (2019). Manajemen Sumber Daya Manusia. Jawa Timur: UBHARA Manajemen Press.

Wibowo. (2017 ). Manajemen Kinerja edisi 5. Depok : Rajawali pers. 